http://jmscr.igmpublication.org/home/

ISSN (e)-2347-176x ISSN (p) 2455-0450

crossref DOI: https://dx.doi.org/10.18535/jmscr/v7i8.159

Journal Of Medical Science And Clinical Research

\title{
Mini Incision Open Appendectomy
}

\author{
Authors \\ Dr C. P. Mohan. M.S., ${ }^{1}$ Dr R. Jayavarmaa. M.S., ${ }^{2}$ \\ Department of General Surgery, Rajah Muthiah Medical College, Annamalai University, \\ Chidambaram - 608002, India
}

\begin{abstract}
Objectives: Appendicitis, being the frequent surgical emergency condition, warrants surgery immediately or electively in order to alleviate complications. Appendectomy can be done through laparoscopic or open access. The incision for open appendectomy varies according to clinical condition of the patient and the surgeon's preference. This study aims at bringing out the advantage, utility and cosmesis of using a mini incision for open appendectomy at our hospital.

Materials and Methods: This is a prospective study on patients getting admitted with clinical and radiological evidence of appendicitis. A total of 50 cases were studied during the period from 2016 to 2019. All the patients underwent open appendectomy through a mini incision measuring 2 to $2.5 \mathrm{~cm}$ preferably under regional anaesthesia. The patients' complete history, clinical profile, operative details, post-operative status, length of hospital stay, condition during follow up were recorded.

Results: Out of 50 patients who underwent mini-incision appendectomy, 31 (62\%) were male and 19 $(38 \%)$ were female. 6 cases $(12 \%)$ required an extension of the incision up to $3.5 \mathrm{~cm}$ due to difficulty in delivering. Surgical site infection occurred in 3 patients (6\%), which were treated conservatively. The average operative period was 28 minutes (20-45 minutes). All the patients had negligible post-operative pain. The condition during follow up was uneventful and the patients had very minimal scar.

Conclusions: The mini-incision appendectomy is thus a safe technique for performing open appendectomy with cosmetic advantage.

Keywords: Appendicitis, Appendectomy, Mini incision.
\end{abstract}

\section{Introduction}

Appendicitis, being the frequent surgical emergency condition, warrants surgery immediately or electively in order to alleviate complications $^{[1]}$. Since it's advent in 1886 by Reginald Fitz, much has been described about the inflamed appendix and the necessity of prompt management to prevent the morbidity due to perforation $^{[2]}$. Any delay in surgery for acute appendicitis could be deleterious for the patient ${ }^{[3]}$. Surgical interventions have evolved over the period from open appendectomies to laparoscopic and normal orifice endoscopic interventions. Claudius Amyand, an English army surgeon, performed the first appendectomy while doing an inguinal hernia repair ${ }^{[4]}$. Mc Burney's devised the grid iron incision for appendectomy; that remained the incision of choice for 120 years ${ }^{[5]}$. This conventional approach favours a $5 \mathrm{~cm}$ incision at the lateral border of the right rectus muscle approximately at the midpoint between the umbilicus and right anterior-superior iliac spine 
[6]. Many new incisions were devised during the following period, that include Rutherford Morison's, Rocky Dave's, Battle's incision and lately Lanz incision for appendectomy ${ }^{[7]}$.

With the advent of laparoscopic appendectomy by Kart Semm, the focus shifted to minimal access surgeries ${ }^{[8]}$. Even with the widespread application and considerable advantages of laparoscopy, there is debate over the best method of appendectomy in the literature ${ }^{[9]}$. Despite the facts open appendectomy is still the most sought procedure especially in rural areas of India, due to lack of skill and equipments ${ }^{[10]}$. Many contemporary surgeons have tried cosmetically better incisions for open appendectomy ${ }^{[11,12]}$. This study is based on performing appendectomy with a transverse incision 2 to $2.5 \mathrm{~cm}$ over the lateral border of rectus up to the Mc Burney's point. This study aims at indicating the advantages of this method called mini-incision appendectomy.

\section{Methods}

50 patients, between the age group of 15 and 55 years, with clinical and radiological evidence of appendicitis were subjected for surgery at our hospital studied during the period from 2016 to 2019. Patients with diagnosis of appendicular mass, appendicular abscess and obese patients were excluded. 42 patients were operated under spinal anaesthesia and 8 patients under general anaesthesia. Transverse incision of 2 to $2.5 \mathrm{~cm}$ was made over the lateral border of right rectus muscle at McBurney's point a in Fig 1 and Fig 2

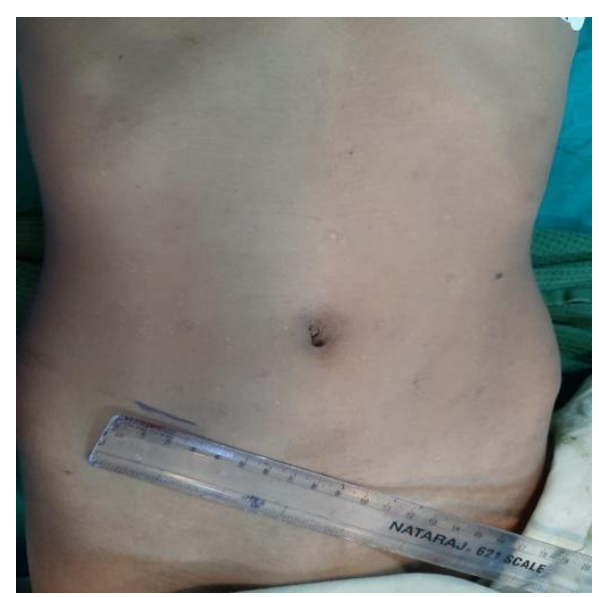

Fig 1: Marking of mini incision
External oblique aponeurosis was incised in line with the skin incision and rectus muscle was split and retracted with small Langenbeck retractors. Transversalis fascia and peritoneum were incised.

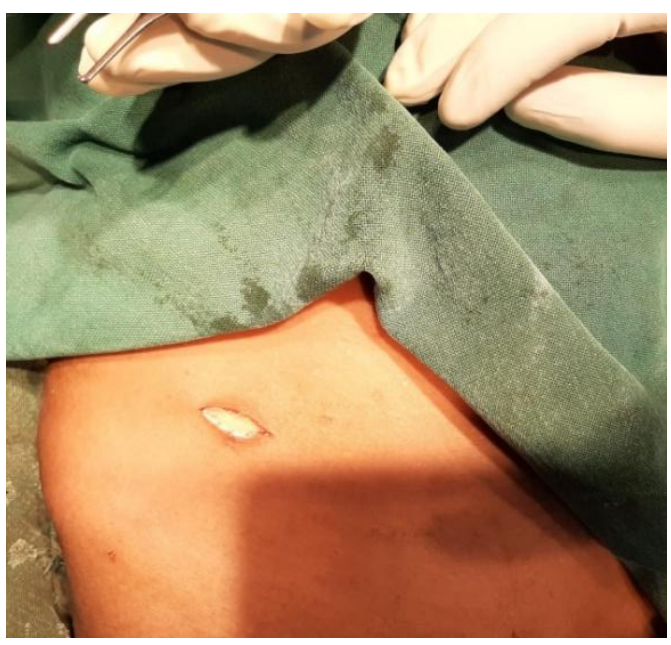

Fig 2: Incision made

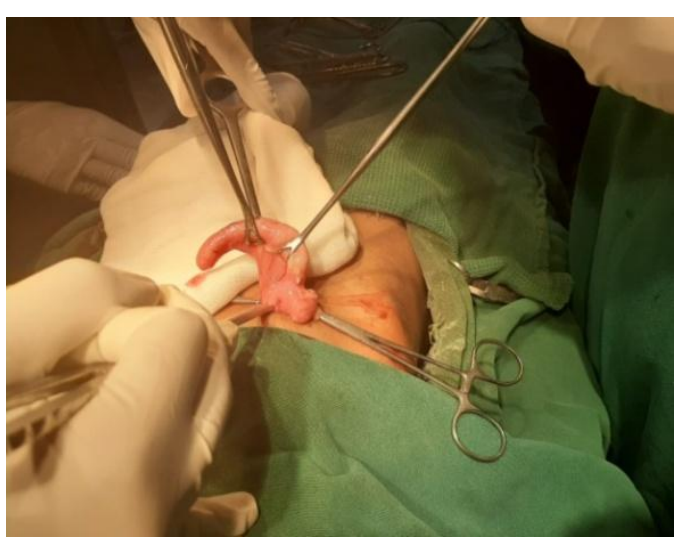

Fig 3: Appendix delivered through the mini incision

With index finger, appendix is palpated and delivered with help of Babcocks forceps. In difficult cases caecum was identified by tracing taenia and subsequently appendix was delivered (Fig 3). Appendectomy was performed as per standard procedure. Peritoneum and external oblique aponeurosis were closed with absorbable suture. Skin was closed with interrupted nonabsorbable sutures. Patients were started on oral liquids on first postoperative day. Incision length, operative time, post-operative pain score, wound infection, length of hospital stay and postoperative pain were analyzed. The patients were analyzed during the follow up after 2 weeks and then after 3 months for their status and scar status. 


\section{Results}

The patients included 31 males (62\%) and 19 females $(38 \%)$ in this study. 33 patients $(66 \%)$ were between 15-30 years, 13 (26\%) were of 3045 years, 4 ( $8 \%$ ) were of $>45$ years. Mini- incision appendectomy was performed in all 50 patients with 6 patients $(12 \%)$ required an extension of the incision to $3.5 \mathrm{~cm}$. The length of incision was $2 \mathrm{~cm}$ in 24 patients $(48 \%)$ and 2.1 to $2.5 \mathrm{~cm}$ in 20 patients $(40 \%)$. Surgical site infection occurred in 3 patients $(6 \%)$ which were treated conservatively. The average operating time was 28 minutes (2045 minutes). Hospital Stay averaged between 2-4 days. All the patients had negligible postoperative pain. The condition during follow up was uneventful and the patients had very minimal scar.

Table 1: Age distribution of the patients

\begin{tabular}{|l|c|}
\hline AGE (YEARS) & NO. OF PATIENTS \\
\hline $\mathbf{1 5}-\mathbf{3 0}$ & 33 \\
\hline $\mathbf{3 0}-\mathbf{4 5}$ & 13 \\
\hline $\mathbf{4 5}$ & 4 \\
\hline
\end{tabular}

Table 2: Incision size variation

\begin{tabular}{|l|c|}
\hline INCISION SIZE & NO. OF PATIENTS \\
\hline $\mathbf{2} \mathbf{~ c m ~}$ & 24 \\
\hline $\mathbf{2}$ to $\mathbf{2 . 5} \mathbf{~ c m}$ & 20 \\
\hline$>\mathbf{3} \mathbf{~ c m ~}$ & 6 \\
\hline
\end{tabular}

\section{Discussion}

Appendicitis, being the frequent surgical emergency condition, warrants surgery immediately or electively in order to alleviate complications. Mc Burney's devised the grid iron incision for appendectomy; that remained the incision of choice for 120 years $^{[5]}$. Many new incisions were devised during the following period, that include Rutherford Morison's, Rocky Dave's, Battle's incision and lately Lanz incision for appendectomy ${ }^{[7]}$. Lanz incision is proved to have an advantage of better cosmetic result. Huochuan L et al (2004) in his study on mini appendectomy he devised an incision with length between $2.5 \mathrm{~cm}$ to $3 \mathrm{~cm}$ (average $2.7 \mathrm{~cm}$ ) ${ }^{[13]}$. In this study the incision length was between $2 \mathrm{~cm}$ to 2.5 cm (average $2.3 \mathrm{~cm}$ ).
A study by Bhasin SK et al in 2005 on miniappendectomy concluded that this reduces hospital stay to 2 to 7 days (average -2.3 days) ${ }^{[14]}$. The patients were discharged between 2 to 4 days (average 3 days) in this study. Saurland $S$ et al analyzed by comparing laparoscopic and open appendectomy concluded that the mean operative time and cost in laparoscopic appendectomy were higher $^{[15]}$. Shah B et al concluded that small incision open appendectomy is better than laparoscopic appendectomy in his research ${ }^{[16]}$.

\section{Conclusion}

Appendicitis, being the common reason for acute abdominal condition, has been dealt with various modalities from conservative management to minimally invasive surgery. Even though laparoscopic approach is widely followed worldwide, in developing countries, especially in rural areas, due to the unavailability of equipments and training, open appendectomy is followed mostly. Devising an incision that favours easy accessibility and minimal postoperative morbidity and scar is ultimate. Mini-incision appendectomy has these advantages and the procedure can be performed under regional anaesthesia. There was negligible morbidity, post-operative pain, minimal scar and the condition during follow up was uneventful. Hence mini-incision appendectomy by the fore mentioned technique is a better in comparison with conventional appendectomy in appropriate cases.

\section{Source: None}

\section{References}

1. Rothrock SG, Pagane J. Acute appendicitis in children: emergency department diagnosis and management. Ann Emerg Med. 2000;36:39-51

2. Fitz RH. Perforating inflammation of the vermiform appendix: with special reference to its early diagnosis and treatment. Am J Med Sci. 1886;92:321346 
3. Ditillo MF, Dziura JD, Rabinovici R. Is it safe to delay appendectomy in adults with acute appendicitis? Ann Surg. 2006;244.

4. Amyand C. Of an inguinal rupture, 1ith a pin in the appendix coeci, incrusted with stone; and some observations on wounds in the guts. Phil Trans Royal Soc. 1736;39:329.

5. C. McBurney, "The incision made in the abdominal wall in cases of appendicitis, with a description of a new method of operating," Annals of Surgery, vol. 20, pp. 38-43, 1894.

6. C. M. Townsend and B. Ever, Atlas of General Surgical Techniques, 2010.

7. Rintoul RF. Operation on the appendix. In: Farquaharson's (editor). Textbook of operative surgery 8 th edition Churchill Livingstone. 1995:452- 4.

8. S. V. Sakpal, S. S. Bindra, and R. S. Chamberlain,

"Laparoscopic cholecystectomy conversion rates two decades later: an analysis of surgeon and patient-specific factors resulting in open conversion," Journal of the Society of Laparoendoscopic Surgeons, vol. 14, no. 4, pp. 476-483, 2011

9. Mantoglu B, Karip B, Mestan M, İscan Y, Agca B, Altun H, et al. Should appendectomy be performed laparoscopically? Clinical prospective randomized trial. Ulus Cerrahi Derg. 2015;31:224-8.

10. Ciftci F. Laparoscopic vs mini-incision open appendectomy. World J Gastrointest Surg. 2015;7(10):267-72.

11. Jelarko C, Davis L. A transverse lower abdominal appendectomy incision with minimal derangements. Surg Gynaecol Obstet. 1973;136:45.

12. Temple WJ. Bikini appendectomy incision, an alternative to the Mc Burney's approach for appendectomy. Canadian $\mathbf{J}$ Surg. 1990;33(5):333-4.
13. Huochuan L, Huichang L, Maxwell micro incision appendectomy experience of 86 cases. Guangzhou Medical Journal. 2009;02:33.

14. Bhasin SK, Dhar S. Mini-appendectomy (an Experience of 100 cases). JK Practioner. 2005;12(1):11-3.

15. Sauerland S, Lefering R, Neugebauer E. Laparascopic versus open surgery for suspected appendicitis. The Cochrane Collaboration. 2007;4:1-74.

16. Shah B, Vaidhya N, Anchalia MM. Comparative study between laparscopic appendicectomy and small incision open (mini lap) Appendicectomy in cases of acute appendicitis. Int J Sci Research. 2013;2(11):2319-64. 